\title{
Are Vietnamese Farmers Concerned with their Relative Position in Society?
}

\author{
Fredrik Carlsson $^{\mathrm{A}}$ \\ Pham Khanh $\mathrm{Nam}^{\mathrm{B}}$ \\ Martin Linde-Rahr ${ }^{\mathrm{C}}$ \\ Peter Martinsson ${ }^{\mathrm{D}}$
}

\author{
Working Papers in Economics no. 165 \\ March 2005 \\ Department of Economics \\ Gothenburg University
}

\begin{abstract}
This paper examines the attitude towards relative position or status among rural households in Vietnam. On average, the respondents show weaker preferences for relative position than in comparable studies in Western countries. Possible explanations are the emphasis on the importance of equality and that villagers are very concerned with how the local community perceives their actions. We also investigate what influences the concern for relative position and find, among other things, that if anyone from the household is a member of the Peoples Committee then the respondent is more concerned with the relative position.
\end{abstract}

Keywords: Relative income, positionality, experiments, Vietnam, Asia. JEL-classification: C91, D63.

\footnotetext{
Acknowledgements: Financial support from the Swedish International Development Agency is gratefully acknowledged. The authors are much indebted to Tran Vo Hung Son for research collaboration and Olof Johansson-Stenman for valuable comments on an earlier draft.

A Department of Economics, Göteborg University, Box 640, 40530 Göteborg, Sweden; Ph +46 31 7734174; Fax +46 31 7731043; E-mail fredrik.carlsson@economics.gu.se.

${ }^{B}$ Faculty of Development Economics, University of Economics - HCMC, 1A Hoang Dieu, Phu Nhuan, Ho Chi Minh City, Vietnam, Ph + 848 9972227, Fax + 848 8453897; E-mail khanhnam@ueh.edu.vn

C Department of Economics, Göteborg University, Box 640, 40530 Göteborg, Sweden; Ph +46 31 7735255; Fax +46 31 7734064; E-mail martin.linde-rahr@ handels.gu.se.

D Department of Economics, Göteborg University, Box 640, 40530 Göteborg, Sweden; Ph +46 31 7735255; Fax +46 31 7731043; E-mail peter.martinsson@economics.gu.se.
} 


\section{Introduction}

Despite the fact that prominent economists such as Smith, Keynes and Scitovsky discussed the importance of status and relative income early, the interest in empirically testing these issues is relatively recent. A number of recent tailor-made empirical studies have shown that people do have preferences for relative position or status, both with respect to income and to consumption (see e.g. Alpizar et al., 2005; Carlsson et al., 2003; Johansson-Stenman et al., 2002; Solnick and Hemenway, 1998). Similarly, empirical studies have shown that relative income has a positive influence on selfreported happiness (e.g. Ferrer-i-Carbonell, 2004; McBride, 2001). In this paper, we extend this literature by empirically investigating the preferences for relative position among farmers in a rural province in the south part of Vietnam. In our study, we let the respondents choose between different, hypothetical investment opportunities with different outcomes for themselves as well as for the other people in their village by applying the experimental approach introduced by Johansson-Stenman et al. (2002). This means that they will choose between alternatives with different relative outcome for themselves.

Most of the previous empirical studies on status or relative position have been conducted in Western European countries and in the USA. A country such as Vietnam differs in many respects from the above mentioned countries. Vietnam is a much poorer country and in 2002 it was ranked $151^{\text {st }}$ in the world based on adjusted gross national purchasing power parity income per capita. ${ }^{1}$ However, the most interesting aspect is perhaps not the low income level per se, but that Vietnam's political system is radically different from any of the Western European countries and the USA. Vietnam is a

\footnotetext{
${ }^{1}$ Using international USD, which is a dollar having the same purchaing power as one USD in the USA, Vietnam's gross per capita income is $6.4 \%$ of the gross per capital income in the USA (World Bank, 2004).
} 
communist society in which the idea of equality forms the basis on which most, or perhaps all, of the country's policies rest on. Bowles (1998) argued that markets, and other economic institutions, influence the evolution of our values and tastes. Thus, individuals' perceptions of factors such as equality and status would then, at least to a certain extent, be affected by the society where they live. Hence we would then expect the preferences for relative position or status to be lower in Vietnam than in Western European countries and in the USA since the idea of equality is widely spread due to its political importance. ${ }^{2}$

The Communist Party of Vietnam was established in 1930, and in 1945 the Democratic Republic of Vietnam was established in what is today the northern part of Vietnam. During the period 1945 to 1975, the Democratic Republic of Vietnam changed its political system towards a Marxist-Leninist system. This political system was introduced in the whole Vietnam (the Socialist Republic of Vietnam) after the unification in 1975, which resulted in a sharp change of direction for the capitalistic oriented economy in southern Vietnam. A decade later, after a period of stagnation in the economy, the so-called Doi Moi (renovation) started in 1986 initiated by the Communist Party. ${ }^{3}$ Before the introduction of Doi Moi, agricultural activities were organized in cooperatives with an egalitarian distribution principle, which ensured a low level of inequality among farmers on the countryside (Nam, 2001). However, the proportion of farmers belonging to cooperatives differed between the north and the south of Vietnam. In 1986, around 95\% of the farmers in North Vietnam were members of a cooperative measured at the regional level. The highest number of farmers

\footnotetext{
${ }^{2}$ However, there can also be an opposite effect from being concerned with equality, since if one strongly dislikes being in a worse position than others, this would then induce concern for status.

${ }^{3}$ Doi Moi meant abandonment of central planning and collective agriculture and the adoption of market socialism.
} 
belonging to cooperatives in the south was $89 \%$ in the Central Coast while only $6 \%$ of the farmers were organized in collectives in the Mekong Delta (Pingali and Xuan, 1992). In the late 1980's, collective farming was abandoned, and land use rights were allocated to farming households during the large land reform. The allocation of land was decentralized to local level politicians. Despite potential incentive problems when allocating, Ravallion and van de Walle (2004) found small effects on income inequality and a substantially improved situation for the poor after the land reform.

Despite the fact that Vietnam has recently shifted towards a market-oriented economy, it may still be expected that the ideas of equality affect people's preferences towards status. Them (1997) argues that the relationship among Vietnamese people to a large extent involves respect towards other people in the community, especially in the rural areas. For example, in any major decision-making process, people are concerned with how the other individuals will respond to their actions, and when there is an event such as a funeral, harvest or construction in the neighborhood, they feel that it is their duty to participate. The reason for such consciousness, especially in rural communities, is perhaps historical, since they often had to struggle for their survival in an environment often left without any significant help from the district officials or the government. A consideration for equality and what others think might explain why Carpenter et al. (2004) found very high levels of contribution in public goods experiments conducted in Ho Chi Minh City, in comparison with experiments in the USA and in Western European countries. ${ }^{4}$ In their paper, they brought forward the tradition of working together as one potential explanation for their findings.

\footnotetext{
${ }^{4}$ In a public good experiment, the subjects decide on how much of their endowment to invest in a public good and how much to keep for a private good. The experiment is set up in such a way that each unit invested in the public good returns less than unity to the investing subject. However, all other subjects in the group also benefit from the investment by a single subject by obtaining the same return as the subject
} 
The rest of the paper is organized as follows. In Section 2 we discuss the underlying economic theory and how the experiment was designed, followed by presentation of the results in Section 3. Finally, Section 4 concludes the paper.

\section{Modeling and measuring positional preferences}

There are many ways to incorporate relative position or status into the utility function. Most studies have either used some kind of ratio comparison utility function, $U=v(x, r) \equiv v(x, x / \bar{x})$, where $x$ is the individual's income (or consumption vector of different goods) and $\bar{x}$ is the average income in the society (e.g. Boskin and Sheshinski, 1978; Layard, 1980; Persson, 1995), or some kind of additive comparison utility function, $U=v(x, r) \equiv v(x, x-\bar{x}) \quad$ (e.g. Akerlof, 1997; Knell, 1999; Ljungqvist and Uhlig, 2000). ${ }^{5}$ In this paper we apply the following additive comparison utility function

$$
v=(1-\gamma) x+\gamma(x-\bar{x}),
$$

where $\gamma$ measures the marginal degree of positionality, i.e. the fraction of the total change in utility that comes from increased relative consumption from the last monetary unit spent. ${ }^{6}$ In order to elicit individuals' preferences for relative position, a scenario has to be created on which the respondents will base their answers. In order to make it cognitively easier for the respondents, we stated that they could think of an investment

\footnotetext{
who invested. Moreover, if all subjects in the group invest one unit, then the return to each subject exceeds one. Thus, the Pareto optimal solution is for each subject to invest his full endowment in the public good, while the Nash solution is to invest nothing in the public good. Normally, investments in public goods are in the range of 40 to $60 \%$ during the first periods and decline over time. However the experiment in Ho Chi Minh investments were in the range of $60 \%$ to $80 \%$, and did not decline over time.

${ }^{5}$ The only empirical test between these two functions that we are aware of is Johansson-Stenman et al. (2002), who found that the ratio-formulation performed better in terms of explaining respondents' behavior. However, they concluded that more research is needed on this issue.

${ }^{6}$ However, the results presented in Section 3 are similar when we applied a ratio comparison utility function in the analysis.
} 
project in for example pigs or any other animal such as cows or perennial crops. The investment project was stated to be distributed free of charge by an external donor without imposing any cost on the people in the village, but the income from this investment would differ among the residents in their village. In the scenario, we told the respondents that they were about to choose between two different alternatives, i.e. investment projects, with different outcomes in terms of income for both themselves and the average person in the village. The two alternatives were shown on a card as well as read out loud. On the cards the outcome for the respondent and the mean outcome for the village in VDN were presented, as well as pigs faces, which were scaled according to the monetary amount. We used this appraoch since some respondents are illiterate. The scenario read by the enumerators is presented in the box below.

In the following questions, we again ask you to make a number of independent choices. ${ }^{7}$ However, this time, the yearly income from the investment in poultry is known for certain. Note, the investment in pigs is just to symbolize an investment decision. It does not have to be pigs, it could be cows or perennial crops, or any other type of investment. The investment is distributed free of charge by an external donor and thus there is no investment cost involved to you, your household or the village.

The difference between the alternatives is the yearly income for you and the average yearly income in your village. The income from the investment can affect your well being, which means you might feel you are richer than the others in the village.

We will now ask you to choose between two alternatives. We will ask you several questions, but there is only one investment made. Alternative A is always the same.

Let me illustrate this choice by the following example.

Alt. A.

- Your yearly income from the investment is $2,500,000$

- The yearly average village income from the investment is $3,000,000$

Alt. B.

- Your yearly income from the investment is $2,300,000$

- The yearly average village income from the investment is $2,000,000$

In this example you get the 200,000 more in Alternative A than in Alternative B. In Alternative A you get 500,000 less than the average income in the village, while in Alternative B you get 200,000 more than the average income.

Choose the alternative that is best for your household.

\footnotetext{
${ }^{7}$ Before the question on positionality, there were questions on risk preferences.
} 
How can we measure the concern for status by using an experiment? Consider the choice between two investment opportunities presented in the example above. The individual's income from the investment in alternative A is 2,500,000 Vietnamese Dong $(\mathrm{VDN})^{8}$ and the average income in the village is $3,000,000 \mathrm{VDN}$. In alternative $\mathrm{B}$, the individual's income is $2,300,000 \mathrm{VDN}$, but at the same time the average income in the village is also lower, 2,000,000 VDN. If a respondent is indifferent between these two investment opportunities, then we have, in the case of the additive comparison utility function, that ${ }^{9}$

$$
x_{A}-\bar{x}_{A}=x_{B}-\bar{x}_{B} \rightarrow \gamma=\frac{x_{A}-x_{B}}{\bar{x}_{A}-\bar{x}_{B}}=0.2
$$

Thus, if a respondent is indifferent between these two investment opportunities, then the marginal degree of positionality, $\gamma$, is equal to 0.2 . Consequently, if the respondent prefers investment $\mathrm{A}$ then $\gamma<0.2$, and vice versa. By asking repeated questions with different outcomes for both themselves and the average person in the village, it is possible to gain more detailed information about the respondents' degree of positionality.

In our experiment, investment alternative A remains the same in all choice sets with a yearly income from the investment of 2,500,000 VDN and with an average income in the village of $3,000,000 \mathrm{VDN}$, while these levels were varied in the $\mathrm{B}$ alternatives. The B alternatives used in the experiment are presented in Table 1, together with the implicit marginal degree of positionality calculated by assuming indifference between the two alternatives (as in the example above). If an individual chooses

\footnotetext{
${ }^{8}$ The exchange rate was $15,158 \mathrm{VDN}=1 \mathrm{USD}$ at the time of the survey.

${ }^{9}$ One advantage of the additive comparison utility function is that the degree of positionality is independent of the intial wealth or total income, i.e. we do not need to adjust the estimates from the experiment for this. At the same time this can of course be seen as a critique against the additive comparison function as being unrealistic.
} 
alternative $A$ over alternative $B_{i}$, then we know that the implicit marginal degree of positionality is below this level, and vice versa. In the experiment, the respondents were presented with choice sets until alternative A was picked, starting with a choice between alternative $A$ and $B_{1}$. As long as a respondent chose alternative $B_{i}$ over alternative $A$, another choice set was presented, but each respondent was presented with a maximum of four choices.

$\gg>$ TABLE 1

\section{Results}

The experiment was conducted in the Binh Phuoc province in southern Vietnam during the spring of 2002. The province is predominantly hilly and most households are engaged in farming activities. Our experiment was a part of a larger household survey with interviews in 212 randomly selected households.

The descriptive results of our experiment are presented in Table 2. The majority of the respondents have a low degree of positionality with $64 \%$ of the sample having a degree of positionality below 0.25 resulting in a median degree of below 0.25 . The mean degree of positionality is calculated to $0.28 .^{10}$ These estimated degrees of marginal positionality are lower than those found in other studies done in other countries. Carlsson et al. (2003) estimate a mean degree of positionality for income in the 0.59 and 0.71 range using a random sample of the Swedish population, while Alpizar et al. (2005) estimate a mean degree of positionality for income of 0.45 using a sample of Costa Rican university students. Using the same assumptions about the utility

\footnotetext{
${ }^{10}$ For non-extreme responses we use the mid-value in each interval when calculating the mean. For the extreme responses $\gamma<0$ and $\gamma>0.66$ we set the values to 0 and 1 , respectively.
} 
function as we have done here, the implicit mean degree of positionality in Solnick and Hemenway (1988) is 0.33. As we discussed in the introduction, there are a number of aspects in the Vietnamese society that could explain why the concern for relative position should be less than in Western countries such as (i) that the Communist Party has emphasized the importance of equality, (ii) the fact that rural households have traditionally been organized in cooperatives, and (iii) that individuals living in the rural areas are very concerned with how the local community perceives their actions (Them, 1997). In light of this, it is perhaps not surprising that the degree of positionality is lower in Vietnam compared with the empirical results from more capitalistic and less community oriented countries.

\section{$\gg$ > TABLE 2}

We estimate what influences the degree of positionality using the interval regression technique, which takes into account that the dependent variable is coded in intervals. We test if the degree of positionality can be explained by three distinct sets of variables: (i) income and wealth, (ii) household characteristics and (iii) memberships in organizations. The household income is calculated by adding income from farming and labor activities, ${ }^{11}$ and in the analyses we apply the equivalence scaled household income, which is calculated as the household income per capita. ${ }^{12}$ Income per capita is

\footnotetext{
${ }^{11}$ Income from agricultural production is calculated as the net value of the income from selling the agricultural products and the cost of production including the cost of hired and in-kind labor. Although some of the labor is in-kind, it is expected that the receiving household will pay back and this is the reason why a price is set on this factor input.

12 A number of different equivalence scale measures were tested using different fractions on a child's consumption in comparison with an adult's consumption as well as on the extent of economies of scale in the household following the ranges discussed in White and Masset (2003), which investigated this issue in Vietnam. The correlation between the different equivalence scaled income that we calculated was high.
} 
categorized into five groups; below 1 million VDN, 1-2 million VDN, 2-3 million VDN, 3-6 million VDN and above 6 million VDN, where the first two levels are income per capita levels below the poverty line. ${ }^{13}$ Wealth is measured by two variables; land and other wealth items. The land variable is constructed as the per capita value of all land possessions of the households. We create a dummy variable for those having values above 22 million VDN per capita, The other wealth items is the per capita value of the aggregated market value of durable goods and livestock, excluding land, owned by the household, where a dummy variable identifies those with a wealth above 5 million VDN per capita. The second group of variables relates to socio-economic characteristics. We create three dummy variables for the age of the respondents, which relate to important changes in Vietnam, resulting in the following groups; 0-32, 33-46 and older than 46 years. Those who were 20 years and younger in 1986, i.e. when Doi Moi started, have lived their entire adulthood during the Doi Moi. Therefore we separate those that are younger than 33 years from those above that age in 2002. In a similar manner, those who were 20 years and older in 1975 have experienced the capitalistic economy before the reunification, i.e. those older than 46 years in 2002 . The level of education indicates whether the respondent has had more than 5 years of formal schooling. In addition we include ethnicity, religious belonging and gender as explanatory variables. The third set of variables is related to if anyone in the household is member of the Peasant Association or the People's Committee. The results of the

Thus, we used the number of household members as the denominator since it is a straightforward measure to apply.

13 The poverty line, based on the cost of basic needs method, was calculated to be $1,789,871$ VDN per person and year in 1998 using the Vietnam Living Standards Survey (Glewwe et al., 2002). Adjusting for inflation, the poverty line would have been around 2 million VDN $(1,968,610 \mathrm{VDN})$ at the time of our survey in 2002 . 
estimations are presented in Table 3 together with descriptive statistics of the explanatory variables.

\section{>> TABLE 3}

Neither income nor wealth has a significant influence on preferences for relative position. However, land is significant and negative, which indicates that those possessing highly valued land have significantly weaker preferences for relative position. The degree of positionality is around 0.13 units lower for those respondents who possess highly valued land, which might be a result of the fact that the land was allocated during the land reform. Moreover, males are less concerned with position than females, and the difference is significant at the $10 \%$ level; the marginal degree of positionality is 0.12 units lower for males. Interestingly, havingat least one in the household who is a member of the People's Committee results in being more status concerned, with a marginal degree of positionality around 0.20 units higher than the others. This is an unexpected result, especially since we would expect that the political system of Vietnam is one explanation why the Vietnamese in general are less concerned with relative position. We can only speculate why this is the case, one being that households with active members of the People's Committee are more concerned with relative position, and that they see the membership as a way of receiving either political, or for that matter, materialistic status. Consequently, if one values either political empowerment or materialistic wealth, membership in the People's Committee might be beneficial. Moreover, party members have been in favor of allowing people to do business in the private sector (Tuyen et al., 2003). Hence, active members of the 
People's Committee might be in the forefront of a new and politically innovative way of looking at the collective, and in light of this, our finding might be less surprising. In any case, interesting research tasks to explain this phenomenon lies ahead. It should also be noted that a similar effect is found in Johansson-Stenman et al. (2002). They find that left-wing voters in Sweden are more concerned with relative position than others.

\section{Discussions}

In this paper, we have investigated individuals' preferences towards relative position or status in a rural province in Vietnam. The results indicate that respondents are not

particularly concerned over their relative position, and that the mean degrees of positionality are lower than those found in comparable studies conducted in Western countries. This might mainly be explained by a political system proclaiming equality as well as the close relationships among people. Them (1997) argued that one distinguishing feature of the Vietnamese people is the respect for the community. Community consciousness is often higher than individual consciousness resulting in people being concerned about living in harmony with their community. An interesting and unexpected finding in our econometric analysis is that households consisting of at least one member of the People's Committee care more about relative position than others.

In Vietnam, before Doi Moi in 1986, cognizance of class differentiation led to a campaign for agricultural collectivization, accompanied by the imposition of an egalitarian distribution principle within these cooperatives. Pham Xuan Nam (2001) argued that this kind of policy made social stratification on the countryside almost nonexistent. Since then Vietnam has moved towards a market-oriented economy, but there 
are clear remnants of the egalitarianism in the rural areas. The strong interaction between individuals found in Vietnam today was perhaps present in Western Europe one or two generations ago. Thus, the development in Vietnam may result in a deterioration of the tight interactions among individuals, which also would result in a lowered level of social capital. Thus, it is therefore exiting to follow a country such as Vietnam since it provides a very good opportunity to study how traditional values transform during times of rapid changes. Moreover, this may also provide the possibility to identify factors that can sustain traditional values. 


\section{References}

Akerlof, G.A. (1997). "Social Distance and Social Decisions". Econometrica 65, 10051027.

Alpizar, F., F. Carlsson and O. Johansson-Stenman (2005). "How Much Do We Care About Absolute versus Relative Income and Consumption?". Journal of Economic Behavior and Organization 56, 405-421.

Boskin, M.J. and E. Sheshinski (1978). "Individual Welfare Depends upon Relative Income". Quarterly Journal of Economics. 92, 589-601.

Bowles. S. (1998) "Endogenous Preferences: The Cultural Consequences of Markets and Other Economic Institutions". Journal of Economic Literature 36, 75-111.

Carlsson, F., O. Johansson-Stenman and P. Martinsson (2003). "Do You Enjoy Having More than Others? Survey Evidence of Positional Goods, Working Papers in Economics No. 100, Department of Economics, Gothenburg University

Carpenter, J.P., A.G. Daniere and L.M. Takahashi (2004). "Social capital and trust in south-east Asian Cities", Urban Studies, 41, 853-874.

Ferrer-i-Carbonell A. (2004). "Income and well-being: An empirical analysis of the comparison income effect, Journal of Public Economics, Forthcoming

Glewwe, P., M. Gragnolati and H. Zaman (2002). "Who gained from Vietnam's Boom in the 1990's?", Economic Development and Cultural Change, 773-792.

Johansson-Stenman, O., F. Carlsson and D. Daruvala (2002). "Measuring Future Grandparents' Preferences for Equality and Relative Standing". Economic Journal, 112, 362-83.

Knell, M. (1999). "Social Comparisons, Inequality, and Growth". Journal of Institutional and Theoretical Economics 155, 664-695.

Layard, R. (1980). "Human Satisfaction and Public Policy". Economic Journal 90, 737 750 .

Ljungqvist, L. and H. Uhlig (2000). "Tax Policy and Aggregate Demand Management Under Catching Up with the Joneses”. American Economic Review 90, 356-366.

McBride, M. (2001). "Relative-income effects on subjective well-being in the crosssection, Journal of Economic Behavior and Organization, 45, 251-278.

Nam, P.X. (2001). Social Development Management Basing on the Progressiveness and Equality Principle. The National Politics Publishing House. Ha Noi.

Persson, M. (1995), "Why are Taxes so High in Egalitarian Societies?" Scandinavian Journal of Economics 97, 469-76.

Pingali, P. L. and V.-T., Xuan (1992). "Vietnam: Decollectivization and rice productivity growth, Economic Development and Cultural Change, 40, 697-718.

Ravallion, M. and D. van de Walle (2004). "Breaking up the collective farms - Welfare outcomes of Vietnam's massive land privatization". Economics of Transition, 12, 201-236.

Solnick, S. and D. Hemenway (1998). "Is More Always Better?: A Survey on Positional Concerns". Journal of Economic Behavior \& Organization 37, 373-83.

Them, T.N. (1997). Vietnam Culture's Grounds. National University Publishing House. Ho Chi Minh City.

Tuyen, N. T., Q.T. Nguyen and M.C. Luong (2003). Private Ownership and Private Business Sector in the socialist oriented market in Vietnam. Ho Chi Minh City Publishing House. Ho Chi Minh City. 
White, H. and E. Masset (2003). "The importance of household size and composition in constructing poverty profiles: An illustration from Vietnam”. Development and Change, 34, 105-126.

World Bank (2004), 2004 World Development Indicators CD-Rom, Washington, D.C.: The World Bank. 
Table 1. Alternatives in positionality experiment.

\begin{tabular}{cccc}
\hline & Own annual outcome & $\begin{array}{c}\text { Average annual } \\
\text { outcome in village }\end{array}$ & $\begin{array}{c}\text { Implicit marginal } \\
\text { degree of positionality }\end{array}$ \\
\hline Alternative $A$ & $2,500,000$ & $3,000,000$ & 0 \\
Alternative $B_{1}$ & $2,500,000$ & $2,000,000$ & 0.25 \\
Alternative $B_{2}$ & $2,250,000$ & $2,000,000$ & 0.46 \\
Alternative $B_{3}$ & $2,040,000$ & $2,000,000$ & 0.66 \\
Alternative $B_{4}$ & $1,840,000$ & $2,000,000$ & \\
\hline
\end{tabular}


Table 2. Results of relative position experiment

\begin{tabular}{cccc}
\hline Marginal degree of positionality & No. & Freq. & Cum. Freq. \\
\hline$\gamma<0$ & 85 & 0.40 & 0.40 \\
$0<\gamma<0.25$ & 53 & 0.25 & 0.65 \\
$0.25<\gamma<0.46$ & 19 & 0.09 & 0.74 \\
$0.46<\gamma<0.66$ & 21 & 0.10 & 0.84 \\
$\gamma \geq 0.66$ & 34 & 0.16 & 1.00 \\
\hline
\end{tabular}


Table 3. Interval regression estimates of the degree of positionality.

\begin{tabular}{|c|c|c|c|c|}
\hline Variable & Description & Coeff & P-value & Mean \\
\hline \multicolumn{5}{|c|}{ Income and wealth indicators } \\
\hline Household & $=1$ If household income per capita is below 1 million & & & \\
\hline income 1 & VDN (1000 dongs); otherwise zero & -0.032 & 0.626 & 0.259 \\
\hline Household & $=1$ If household income per capita is 1 million VDN & & & \\
\hline income 2 & to 1.9 million VDN (1000 dongs); otherwise zero & -0.058 & 0.433 & 0.222 \\
\hline Household & $=1$ If household income per capita is 1.9 million VDN & & & \\
\hline income 3 & to 3 million VDN (1000 dongs); otherwise zero & 0.003 & 0.976 & 0.156 \\
\hline Household & $=1$ If household income per capita is 3 million VDN to & & & \\
\hline income 4 & 5 million VDN; otherwise zero & -0.018 & 0.784 & 0.189 \\
\hline Wealth & $\begin{array}{l}=1 \text { If household wealth per capita above } 5 \text { million } \\
\text { VDN ; otherwise zero }\end{array}$ & 0.035 & 0.505 & 0.292 \\
\hline Land & $\begin{array}{l}=1 \text { If land wealth per capita exceeds } 22 \text { million VDN; } \\
\text { otherwise zero }\end{array}$ & -0.116 & 0.021 & 0.255 \\
\hline \multicolumn{5}{|c|}{ Household characteristics } \\
\hline Age 47 & $=1$ if respondent older than 46 ; otherwise zero & -0.014 & 0.815 & 0.377 \\
\hline Age 33 & $=1$ if respondent aged 33 to 46 years; otherwise zero & 0.031 & 0.591 & 0.439 \\
\hline Education & $=1$ if more than 5 years schooling & 0.016 & 0.702 & 0.590 \\
\hline Kinh & $=1$ if household belong to the main ethnic group & 0.070 & 0.143 & 0.736 \\
\hline Buddhist & $=1$ respondent is a Buddhist & -0.050 & 0.2109 & 0.316 \\
\hline Male & $=1$ if male; otherwise zero & -0.111 & 0.079 & 0.863 \\
\hline People's & $=1$ if any household member is a member of the & & & \\
\hline Committee & People's Committee & 0.202 & 0.015 & 0.080 \\
\hline Peasant & $=1$ if any household member is a member of the & & & \\
\hline Association & Peasant Association & -0.044 & 0.263 & 0.547 \\
\hline \multicolumn{2}{|l|}{ Constant } & 0.336 & 0.000 & \\
\hline \multicolumn{2}{|l|}{ Sigma } & 0.274 & 0.013 & 0.00 \\
\hline \multicolumn{2}{|c|}{ Number of observations } & 212 & & \\
\hline
\end{tabular}

